\title{
Modification of USY zeolites with malic-nitric acid for hydrocracking
}

\author{
Ke Qiao ${ }^{1} \cdot{\text { Xuejin } \mathrm{Li}^{1}}^{1} \cdot$ Yang Yang $^{1} \cdot$ Fazle Subhan $^{2} \cdot$ Xinmei Liu $^{1} \cdot$ \\ Zifeng Yan $^{1} \cdot$ Wei Xing ${ }^{1} \cdot$ Lihong Qin $^{3} \cdot$ Baoqin Dai $^{3} \cdot$ Zhihua Zhang $^{3}$
}

Received: 20 October 2015/Accepted: 17 December 2015/Published online: 29 January 2016

(c) The Author(s) 2016. This article is published with open access at Springerlink.com

\begin{abstract}
The modification of commercial ultra-stable $\mathrm{Y}$ zeolite using malic acid (MA) and nitric acid (NA) was investigated. A series of factors including the amount of MA and NA solutions, the $\mathrm{pH}$ of the solutions, the treatment time, and the reaction temperature were investigated and optimized. The pore structure, acid properties, and crystal structure of modified USY zeolite were characterized by $\mathrm{N}_{2}$-adsorption, temperature-programmed desorption of ammonia $\left(\mathrm{NH}_{3}-\mathrm{TPD}\right)$, pyridine adsorbed Fourier transform infrared spectroscopy, and X-ray diffraction techniques. The as-obtained sample under the optimum conditions presents an increased secondary pore volume up to $0.202 \mathrm{~cm}^{3} \mathrm{~g}^{-1}$, which accounts for $45.3 \%$ of the total pore volume, and appropriate acid properties as well as good crystallinity. Furthermore, the USY zeolite modified with different methods was also investigated, indicating that malic-nitric combined acid is an effective modifier for USY zeolite. The modified USY zeolite was used as support to prepare hydrocracking catalysts. The $140-370{ }^{\circ} \mathrm{C}$ middle distillate yield of the catalyst is $68.59 \%$, and middle distillate selectivity can reach up to $81.52 \%$. Compared with commercial catalyst, the yield and selectivity increased by 8.17 and $5.14 \%$, respectively.
\end{abstract}

Zifeng Yan

zfyancat@upc.edu.cn

1 State Key Laboratory of Heavy Oil Processing, PetroChina Key Laboratory of Catalysis, China University of Petroleum, Qingdao 266580, China

2 Department of Chemistry, Abdul Wali Khan University Mardan, Mardan, K.P.K, Pakistan

3 Daqing Petrochemical Research Center, PetroChina Petrochemical Institute, CNPC, Daqing 163714, China
Keywords USY zeolite - Modification - Malic acid · Nitric acid

\section{Introduction}

With the depletion of petroleum, coal, natural gas, and other fossil fuels, the global energy crisis is increasing rapidly. However, due to rapid population growth, the consumption of fuels, energy, and petrochemical products has been increasing tremendously. Thus, new challenges for the petroleum refineries to upgrade heavy oils and residues are (1) to produce more middle distillate products [1-3], (2) high-quality transportation fuels, and (3) depletion of crude oil sources [4]. During the past three decades, hydrocracking has gained prominence in light petroleum refining processes [5]. After complete industrialization of light petroleum oil, hydrocracking processes are gradually applied for heavy oil and VR upgradation. However, these processes still needed the development of hydrocracking catalyst with rapid ion/mass transfer channels as well as appropriate acid sites.

Due to the novel pore structure and surface acidy, USY zeolite has been widely used in hydrocracking. However, the performance of commercial USY (CUSY) zeolites is unsatisfactory due to the lack of mesopores and large acidic sites. Cracking is often limited by the diffusion of reactants inside the micropore of zeolite. The mesoporous structure is more suitable for diffusion of reactants. In addition, high acidity can cause coking, which leads to catalyst deactivation. The catalyst deactivation will cause a reduction of product selectivity and quality. Thus, tremendous research about modification of USY zeolite has been reported in literature in the past [6-10]. Dealumination of framework aluminum is an effective way to improve the $\mathrm{Si} / \mathrm{Al}$ ratio 
and acid property. For this purpose, thermal or hydrothermal treatments [9], acids leaching [10], and chemical treatments with hexafluorosilicate or silicon tetrachloride are reported [11-14]. Among these methods, hydrothermal treatment is one of the most promising and sole industrialized methods. In this method, high-temperature steam reacts with the framework aluminum to produce $\mathrm{Al}(\mathrm{OH})_{\mathrm{x}}$ which will remain inside the pores [15]. The modified USY zeolite not only provide mesopores but also appropriate amount of Brønsted acid sites. However, the removed aluminum species will block the pore channels. In addition, the crystallinity reduces rapidly with an increase of temperature. Ludmila Kubelková et al. [13] modified Y zeolite with $\mathrm{SiCl}_{4}$, which could react with the framework aluminum under high temperature. The skeleton vacancies caused by dealumination can be compensated by extraframework silica. The modified USY has good acidic properties and high crystallinity, as well as improved hydrothermal stability. But the lack of abundant mesopores limits its applications in hydrocracking. Organic co-ordination reaction is another useful way to remove framework or extra-framework aluminum. The organic complex reacts with aluminum via complexation under a moderate reaction conditions, and no obvious defects are observed in the modified samples [16, 17]. For example, Liu et al. [17] studied the modification of USY zeolite using citric acid in an unbuffered reaction system. The obtained zeolite possessed improved $\mathrm{Si} / \mathrm{Al}$ ratio, smaller unit cell parameters, and more developed pore structure. Up to date, the aforementioned modification methods still experience a lot of problems and challenges, such as poor hydrothermal stability, less developed mesoporous structure, and harsh operation conditions. Exploring a facile and efficient approach to modify CUSY zeolite is still challenging.

In this work, we reported a combined modification of USY zeolite using malic acid (MA) and nitric acid (NA). MA removes aluminum by coordination reaction to create abundant secondary pores while NA removes the extraframework alumina. A series of experiments were carried out to investigate the effects of various factors on the USY zeolites. Furthermore, the crystal structure, textural, and acid properties of the modified USY (MNUSY) zeolite were also investigated by XRD, $\mathrm{N}_{2}$ adsorption-desorption isotherms, Py-FT-IR, and $\mathrm{NH}_{3}$-TPD.

\section{Experimental}

\section{Materials}

Malic acid (AR), nitric acid (AR), citric acid (AR), and phosphoric acid (AR) were purchased from Sinopharm Chemical Reagent Co. Ltd. Commercial USY zeolites were purchased from Zibo HuaXin catalyst Co. Ltd. All chemicals were used as received.

\section{Sample preparation}

Firstly, MA solution and NA solution with different concentrations were prepared. Then, a fixed quantity of $4 \mathrm{~g}$ CUSY zeolite and different amounts of NA solution were put into a 250-ml three-neck flask. Subsequently, the flask was transferred into a water bath set at a certain temperature. The same volume of MA solution was then added into the flask within $5 \mathrm{~min}$. The modification was completed after a certain time period. Afterwards, the products were filtrated and washed with distilled water. Finally, the product was obtained after drying at $110^{\circ} \mathrm{C}$ in an oven overnight.

\section{Sample characterization}

Nitrogen adsorption-desorption measurements were performed on a TriStar 3000 analyzer (Micromeritics, USA) to obtain specific surface area and pore structure parameters of the as-prepared samples. The total surface area was calculated using Brunauer-Emmett-Teller (BET) method. The mesopore surface area, mesopore volumes, and pore size distribution were obtained from the desorption branch by Barret-Joyner-Halenda (BJH) method. Si/Al ratio, crystal cell parameters, and crystallinity were characterized by X-ray diffraction (XRD) analysis (X'Pert PRO MPD, Holland). FT-IR spectra of samples with pyridine (py) adsorption were measured on Nicolet 6700, U.S.A. Temperature-programmed desorption of ammonia $\left(\mathrm{NH}_{3}-\mathrm{TPD}\right)$ was as carried out on CHEMBET-3000 TPR/TPD Chemisorption analyzer (Quantachrome Instrument, U.S.A.). About $100 \mathrm{mg}$ of sample was pretreated at $200{ }^{\circ} \mathrm{C}$ in nitrogen $(20 \mathrm{~mL} / \mathrm{min})$ for $30 \mathrm{~min}$ in a U-shaped quartz tube. After the sample was cool down to room temperature, ammonia was then injected into the tube. TPD was performed from 50 to $700{ }^{\circ} \mathrm{C}$ at a heating rate of $15{ }^{\circ} \mathrm{C} / \mathrm{min}$ when physisorbed ammonia was purged with nitrogen.

\section{Evaluation of catalyst}

Prior to the hydrocracking test, the modified USY sample (10 wt $\%)$ and amorphous silica-alumina (90 wt $\%$ ) were mixed together using alumina as peptizator, and then the carrier was produced by extrusion machine in the shape of long column. Ni-W as an active component was loaded on carrier by impregnation method. After drying and calcination, the catalyst was prepared.

Performance evaluation of the hydrocracking catalyst was carried out on a $200 \mathrm{~mL}$ fixed-bed single-stage hydrogenation unit using Daqing VGO as feedstock under 
the following conditions: pressure 15.0 $\mathrm{MPa}$, volume space velocity $1.5 \mathrm{~h}^{-1}, \mathrm{~V}\left(\mathrm{H}_{2}\right) / \mathrm{V}($ oil $)=1250$, and reaction temperature $385^{\circ} \mathrm{C}$. $100 \mathrm{~mL}$ catalyst was loaded. The main properties of Daqing VGO were as follows: Density $\left(20{ }^{\circ} \mathrm{C}\right), 0.8519 \mathrm{~g} / \mathrm{cm}^{3}$, distillate range, $240-500{ }^{\circ} \mathrm{C}, \mathrm{S}$ content, $827 \mu \mathrm{g} / \mathrm{g}, \mathrm{N}$ content, $986 \mu \mathrm{g} / \mathrm{g}$.

\section{Results and discussions}

\section{Optimization of operation conditions}

Mesopores USY are important for fast transmission of reactants and products of hydrocracking when it was used in hydrocracking. Thus, the mesopores of USY should be generated as much as possible after the USY zeolite was treated with MA and NA solutions. However, the crystallinity of USY will be reduced with an increase of mesopores during the dealumination. Therefore, we investigated the optimum operation conditions by a singlefactor experiment using mesopore volume and relative crystallinity as a criteria. The modification conditions and results are listed in Table 1 . The experimental conditions, such as the amount of MA and NA solutions, $\mathrm{pH}$ of the solutions, treatment time, and reaction temperature are investigated.

As shown in Table 1, with the increase of MA and NA solutions content, the secondary pore volume increased while the relative crystallinity reduced. When the amount of MA and NA are less than $60 \mathrm{~mL}$, the secondary pore volume decreases to some extent, whereas the relative crystallinity reduces to a great extent. Therefore, $80 \mathrm{~mL}$ of MA and NA was considered as an appropriate level. During the modification process, most of the extra-framework aluminum and a part of framework aluminum were removed via protons from NA and carboxylate ions from MA, leading to an increase of pore volume and decrease of crystallinity. Then, we investigate the influence of $\mathrm{pH}$ on the modification. It is obvious that the $\mathrm{pH}$ of acid solutions has a great influence on the pore volume and crystallinity. With the decrease of $\mathrm{pH}$, the pore volume increases and the relative crystallinity decreases. The results also indicate that the relative crystallinity decreased with the decrease in $\mathrm{pH}$ from 2 to 1.5. To prevent the excessive framework damage and obtain abundant mesopores, $\mathrm{pH}$ was adjusted to an optimum level of 1.5 . In addition, the treatment time is also a very important factor for the modification of USY zeolite. As listed in Table 1, the mesopore volume increases from 0.153 to $0.202 \mathrm{~cm}^{3} \mathrm{~g}^{-1}$ when the reaction time increases from 0 to $4 \mathrm{~h}$. This is due to the fact that the extra-framework and a part of framework aluminum can substantially be removed with the increase of treatment time. However, when the treatment time rises to $8 \mathrm{~h}$, a dramatic decrease of mesopore volume and relative crystallinity is observed. Thus, $4 \mathrm{~h}$ is considered as an optimum treatment time. Furthermore, the modifications of USY zeolite are also performed at different temperatures. The secondary pore volume of modified USY zeolite increases with the increase of reaction temperature as expected. However, the framework structure of USY zeolite will be

Table 1 The secondary pore volume and relative crystallinity of modified USY zeolite at different operation conditions

\begin{tabular}{|c|c|c|c|c|c|c|c|c|}
\hline Samples & $\begin{array}{l}\text { Volume of } \\
\text { MA }(\mathrm{mL})\end{array}$ & $\begin{array}{l}\text { Volume of } \\
\text { NA }(\mathrm{mL})\end{array}$ & $\begin{array}{l}\mathrm{pH}^{\mathrm{a}} \text { of } \\
\mathrm{MA}\end{array}$ & $\begin{array}{l}\mathrm{pH}^{\mathrm{a}} \text { of } \\
\mathrm{NA}\end{array}$ & $\begin{array}{l}\text { Treatment } \\
\text { time }(\mathrm{h})\end{array}$ & $\begin{array}{l}\text { Reaction } \\
\text { temperature }\left({ }^{\circ} \mathrm{C}\right)\end{array}$ & $\begin{array}{l}\text { Secondary pore } \\
\text { volume }\left(\mathrm{cm}^{3} / \mathrm{g}\right)\end{array}$ & $\begin{array}{l}\text { Relative } \\
\text { crystallinity (\%) }\end{array}$ \\
\hline MN-1 & 20 & 20 & 1.5 & 1.5 & 4 & 80 & 0.189 & 65.99 \\
\hline MN-2 & 40 & 40 & 1.5 & 1.5 & 4 & 80 & 0.188 & 63.86 \\
\hline MN-3 & 60 & 60 & 1.5 & 1.5 & 4 & 80 & 0.192 & 59.41 \\
\hline $\mathrm{MN}-4$ & 80 & 80 & 1.5 & 1.5 & 4 & 80 & 0.202 & 56.56 \\
\hline MN-5 & 80 & 80 & 7 & 7 & 4 & 80 & 0.153 & 60.71 \\
\hline MN-6 & 80 & 80 & 4 & 4 & 4 & 80 & 0.164 & 64.14 \\
\hline MN-7 & 80 & 80 & 2 & 2 & 4 & 80 & 0.190 & 66.59 \\
\hline MN-8 & 80 & 80 & 1.5 & 1.5 & 4 & 80 & 0.202 & 56.56 \\
\hline MN-9 & 80 & 80 & 1.5 & 1.5 & 0 & 80 & 0.153 & 60.71 \\
\hline $\mathrm{MN}-10$ & 80 & 80 & 1.5 & 1.5 & 2 & 80 & 0.175 & 63.60 \\
\hline $\mathrm{MN}-11$ & 80 & 80 & 1.5 & 1.5 & 4 & 80 & 0.202 & 56.97 \\
\hline $\mathrm{MN}-12$ & 80 & 80 & 1.5 & 1.5 & 8 & 80 & 0.126 & 48.27 \\
\hline $\mathrm{MN}-13$ & 80 & 80 & 1.5 & 1.5 & 4 & 25 & 0.153 & 60.71 \\
\hline $\mathrm{MN}-14$ & 80 & 80 & 1.5 & 1.5 & 4 & 60 & 0.167 & 58.01 \\
\hline $\mathrm{MN}-15$ & 80 & 80 & 1.5 & 1.5 & 4 & 80 & 0.202 & 56.97 \\
\hline $\mathrm{MN}-16$ & 80 & 80 & 1.5 & 1.5 & 4 & 100 & 0.151 & 52.57 \\
\hline
\end{tabular}

A-refers to the $\mathrm{pH}$ of MA and NA solutions used in the modification 
destroyed heavily at high temperature because of corrosion of $\mathrm{H}^{+}$, leading to a rapid decrease of crystallinity. For this purpose, USY zeolite was modified at $80{ }^{\circ} \mathrm{C}$ in the present study. According to the results of single-factor experiment, it can be concluded that the modification of USY zeolite has the best performance when the amount of MA, NA, $\mathrm{pH}$ of MA, $\mathrm{pH}$ of NA, reaction time, and temperature are $80 \mathrm{~mL}, 80 \mathrm{~mL}, 1.5,1.5,4 \mathrm{~h}$, and $80^{\circ} \mathrm{C}$, respectively. Then, MNUSY was prepared at optimum modification conditions.

\section{Characterization and discussion}

\section{Textural properties of modified USY zeolite}

$\mathrm{N}_{2}$ adsorption-desorption isotherms determined at $77 \mathrm{~K}$ and the pore size distribution of the prepared samples are shown in Fig. 1. Both CUSY and MNUSY present type IV isotherms with an $\mathrm{H} 2$ hysteresis loops in the relative pressure $\left(\mathrm{p} / \mathrm{p}_{0}\right)$ range of $0.43-1.0$, characteristics of developed mesoporous structures. Compared with CUSY, MNUSY possesses larger $\mathrm{N}_{2}$-adsorption quantity and mesopore volume. As shown in Table 2, MNUSY has a high specific surface area of $613 \mathrm{~m}^{2} \mathrm{~g}^{-1}$ and a large mesopore volume of $0.202 \mathrm{~m}^{3} \mathrm{~g}^{-1}$. The pore size distribution curves also confirmed the existence of mesopores, centered at 8.0 and $23.0 \mathrm{~nm}$. Nitric acid, as a small molecular inorganic acid, can attract the framework aluminum on the surface of USY zeolite to weaken the framework structure. A part of extra-framework aluminum

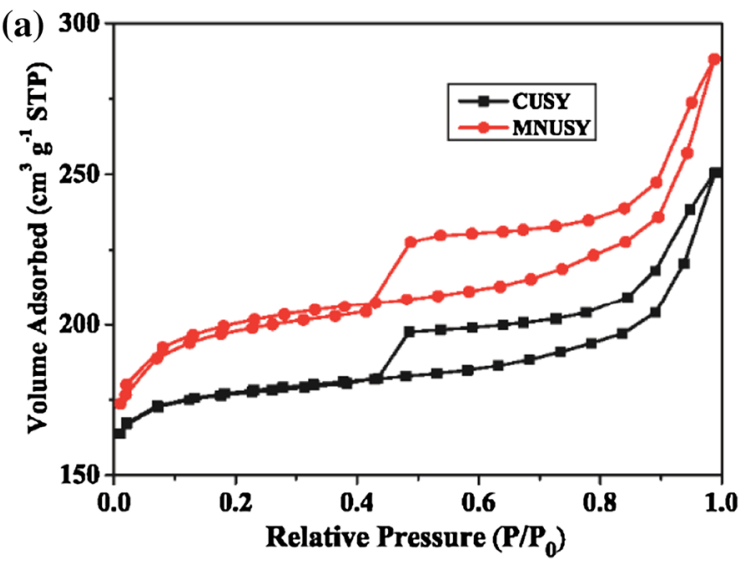

can also be removed by NA, leading to an unobstructed pore channel to facilitate the entrance of MA molecular. MA molecular possesses two carboxyls and a hydroxyl which can coordinate with extra-framework aluminum, resulting in abundant of tetrahydroxy vacancies. The micropores generate with the processing of dealumination as shown in Table 2. With further removal of extraframework aluminum and framework aluminum, micropores connect with each other to form mesopores.

\section{Acid characterization of modified USY zeolite}

The acidic properties of samples were characterized by PyFT-IR and $\mathrm{NH}_{3}$-TPD techniques (Fig. 2). As shown in Fig. 2a, all the samples exhibited three IR bands at 1443, 1545 , and $1490 \mathrm{~cm}^{-1}$. The bands of CUSY at 1443 and $1545 \mathrm{~cm}^{-1}$ corresponded to the characteristic of pyridine molecules chemisorbed on Lewis (L) and Brønsted (B) acidic sites, respectively, while the band at $1490 \mathrm{~cm}^{-1}$ can be assigned to both $\mathrm{B}$ and $\mathrm{L}$ acidic sites [18]. In comparison with CUSY, the bands of MNUSY attributed to $\mathrm{L}$ and $\mathrm{B}$ acidic sites were shifted to 1445 and $1546 \mathrm{~cm}^{-1}$, respectively, indicating that the existing modification process can strengthen the acidic sites in the sample. The acidic strength of samples was measured by $\mathrm{NH}_{3}$-TPD. As shown in Fig. $2 b$, all samples exhibited two ammonia desorption peaks at 200 and $450{ }^{\circ} \mathrm{C}$. According to the peak area, the amount of both strong acid and weak acidic sites was decreased. However, the decrease of weak acid was

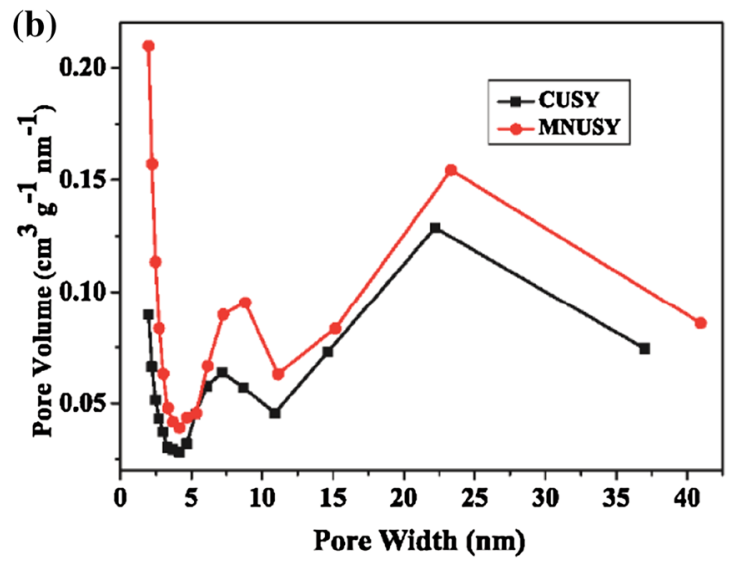

Fig. 1 a $\mathrm{N}_{2}$ adsorption-desorption isotherms and b pore size distributions of modified USY zeolite

Table 2 Texture properties of modified USY zeolite

\begin{tabular}{lllllll}
\hline Samples & $\begin{array}{l}\text { BET surface } \\
\text { area }\left(\mathrm{m}^{2} / \mathrm{g}\right)\end{array}$ & $\begin{array}{l}\text { Micropore } \\
\text { area }\left(\mathrm{m}^{2} / \mathrm{g}\right)\end{array}$ & $\begin{array}{l}\text { Secondary pore } \\
\text { area }\left(\mathrm{m}^{2} / \mathrm{g}\right)\end{array}$ & $\begin{array}{l}\text { Total volume } \\
\left(\mathrm{cm}^{3} / \mathrm{g}\right)\end{array}$ & $\begin{array}{l}\text { Micropore volume } \\
\left(\mathrm{cm}^{3} / \mathrm{g}\right)\end{array}$ & $\begin{array}{l}\text { Secondary pore } \\
\text { volume }\left(\mathrm{cm}^{3} / \mathrm{g}\right)\end{array}$ \\
\hline CUSY & 542 & 485 & 85 & 0.388 & 0.249 & 0.153 \\
MNUSY & 613 & 488 & 136 & 0.446 & 0.255 & 0.202 \\
\hline
\end{tabular}



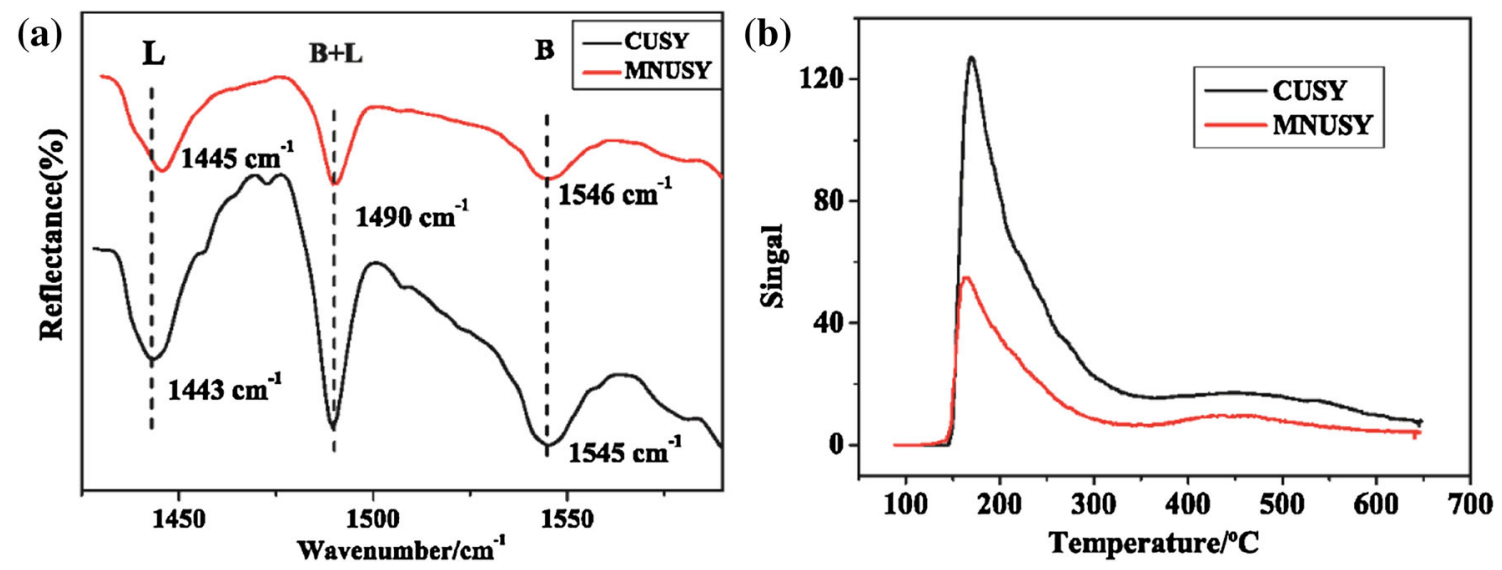

Fig. 2 a Pyridine adsorbed FT-IR diffuse reflection spectra and $\mathbf{b} \mathrm{NH}_{3}$-TPD profiles of modified USY zeolite

much higher than medium acid, which will play an important role in improving the yield of middle distillate.

\section{XRD characterization}

The wide angle-XRD patterns of samples are shown in Fig. 3. As can be seen from Fig. 3, CUSY exhibited high intensity characteristic diffraction peaks of faujasite framework, revealed the existence of high crystallinity in structure. After modification with MA and NA solutions, the diffraction peak intensity corresponding to FAU structure decreased slightly in intensity. By calculating the diffraction peak height, we can say that the relative crystallinity of USY zeolite was decreased from 60.71 to $56.56 \%$ after modification. These results indicate that MA-NA combined solution has slightly destroyed the crystal structure by creating abundant secondary pores. During the dealumination of MA-NA solution, most of the extra-framework aluminum in the pore channels was removed, meanwhile the extra-framework silicon can insert into the vacancy of tetrahydroxy. The inserted silicon can

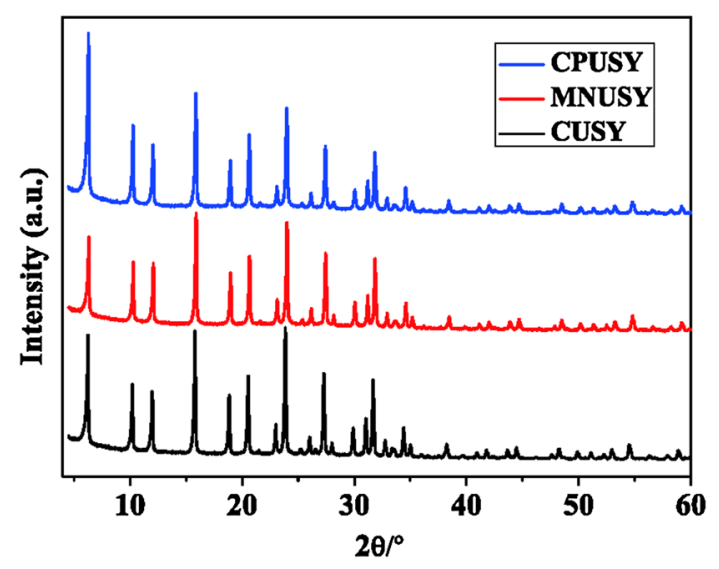

Fig. 3 The XRD pattern of USY zeolites increase the crystallinity to a certain extent. This can be confirmed by the change of framework $\mathrm{Si} / \mathrm{Al}$ ratio. The $\mathrm{Si} /$ Al ratio increased dramatically from 10.8 (CUSY) to 26.5 (MNUSY) after modification. However, as the dealumination processed, maximum amount of aluminum would be removed by $\mathrm{MA}$ and NA, leading to a continuous destruction of crystal structure.

\section{Comparison of modified USY zeolite with different acids}

According to the reports in literature [19], citric acid combined with phosphoric acid seems to be an effective modifier for USY zeolite. Therefore, we compared the modified samples prepared under optimum conditions with two different methods. From XRD pattern (Fig. 3), it can be seen that MNUSY possessed almost the same diffraction peaks as that of citric acid and phosphoric combined acidmodified USY (CPUSY). As shown in Table 3, these two samples have similar relative crystallinity and framework $\mathrm{Si} / \mathrm{Al}$ ratio, indicating the comparable dealumination performance of these two different acid systems. As shown in Fig. 4a, MNUSY presents a larger hysteresis loop at a $\mathrm{P} / \mathrm{P}_{0}$ ranging from 0.43 to 1.0 due to capillary condensation, which is an indicator of large mesopore volume. This phenomenon can also be observed in the pore size distribution curves (Fig. 4b). MNUSY presents larger pore volume at 8 and $23 \mathrm{~nm}$ than CPUSY, suggesting its much more abundant mesopores. The texture properties of modified USY are listed in Table 4. The CPUSY has a

Table 3 Crystal structural parameters of modified USY

\begin{tabular}{lll}
\hline Sample & Degree of crystallinity $\left(\mathrm{C}_{\mathrm{RX}} / \%\right)$ & $\mathrm{Si} / \mathrm{Al}$ ratio \\
\hline CUSY & 60.71 & 10.8 \\
MNUSY & 56.56 & 26.5 \\
CPUSY & 56.21 & 25.3 \\
\hline
\end{tabular}



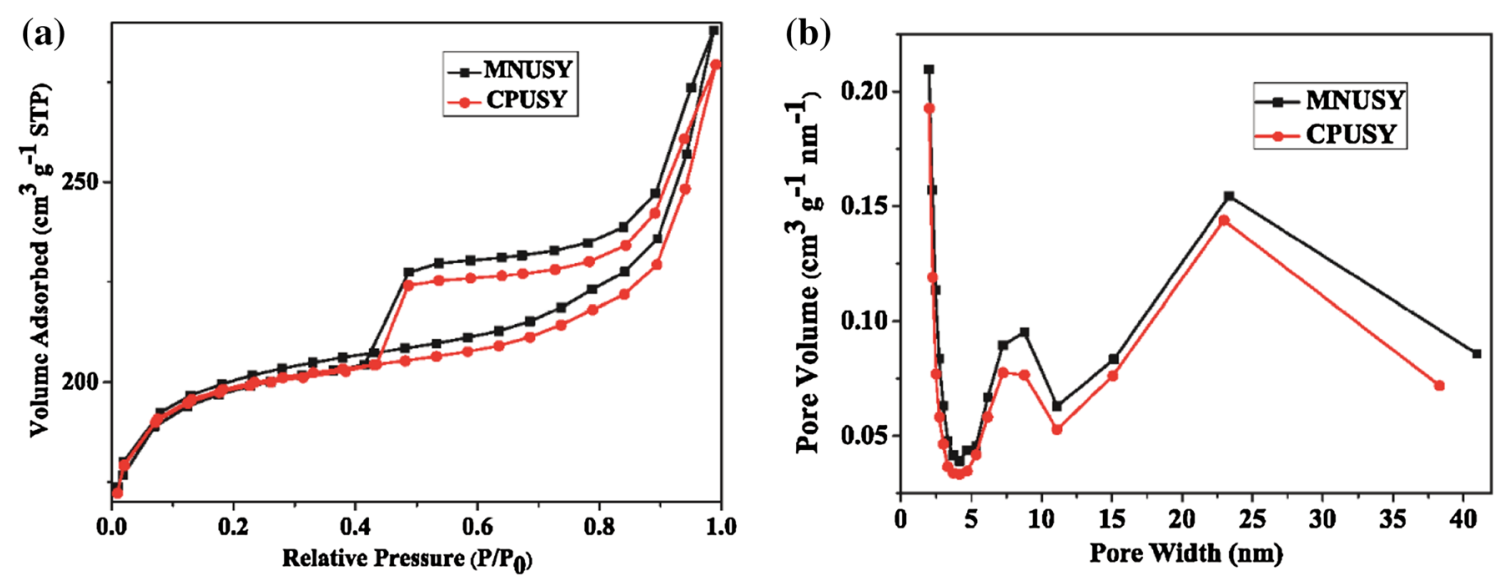

Fig. 4 a $\mathrm{N}_{2}$ adsorption-desorption isotherms and $\mathbf{b}$ pore size distributions of modified USY zeolite with different acids

Table 4 Texture properties of modified USY zeolite

\begin{tabular}{lllllll}
\hline Sample & $\begin{array}{l}\text { BET surface } \\
\text { area }\left(\mathrm{m}^{2} / \mathrm{g}\right)\end{array}$ & $\begin{array}{l}\text { Micropore } \\
\text { area }\left(\mathrm{m}^{2} / \mathrm{g}\right)\end{array}$ & $\begin{array}{l}\text { Secondary pore } \\
\text { area }\left(\mathrm{m}^{2} / \mathrm{g}\right)\end{array}$ & $\begin{array}{l}\text { Total volume } \\
\left(\mathrm{cm}^{3} / \mathrm{g}\right)\end{array}$ & $\begin{array}{l}\text { Micropore } \\
\text { volume }\left(\mathrm{cm}^{3} / \mathrm{g}\right)\end{array}$ & $\begin{array}{l}\text { Secondary pore } \\
\text { volume }\left(\mathrm{cm}^{3} / \mathrm{g}\right)\end{array}$ \\
\hline CPUSY & 606 & 519 & 116 & 0.432 & 0.269 & 0.179 \\
MNUSY & 613 & 489 & 136 & 0.446 & 0.255 & 0.202 \\
\hline
\end{tabular}

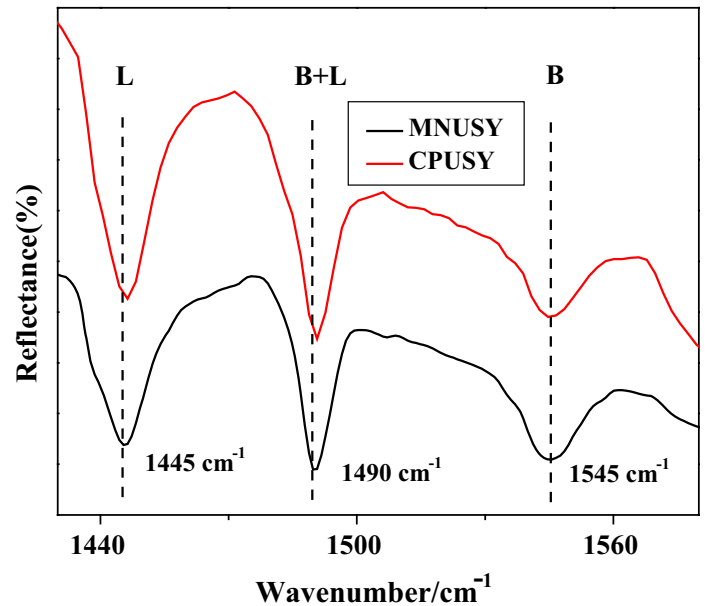

Fig. 5 Pyridine-adsorbed FT-IR diffuse reflection spectra of modified USY zeolite

specific surface area of $606 \mathrm{~m}^{2} \mathrm{~g}^{-1}$ and secondary pore volume of $0.179 \mathrm{~cm}^{3} \mathrm{~g}^{-1}$ while MNUSY presents a higher specific surface area of $613 \mathrm{~m}^{2} \mathrm{~g}^{-1}$ and larger secondary pore volume of $0.202 \mathrm{~cm}^{3} \mathrm{~g}^{-1}$. Higher number of secondary pores of MNUSY led it to be a better hydrocracking catalyst than CPUSY. The Py-FT-IR was also used to characterize the acid properties of CPUSY and MNUSY. As shown in Fig. 5, they both exhibited characteristic peaks located at 1445,1490 , and $1545 \mathrm{~cm}^{-1}$. The amount ratio of $\mathrm{B}$ acid and $\mathrm{L}$ acid were calculated by their corresponding peak areas. It's obvious that the B/L of MNUSY is higher than that of CPUSY, which is profitable for hydrocracking reactions.

\section{Evaluation of catalyst}

According to the $77.1 \%$ conversion of $>350{ }^{\circ} \mathrm{C}$ feedstock (Table 5), MNUSY supported catalyst-exhibited excellent hydrocracking performance. The $140-370{ }^{\circ} \mathrm{C}$ middle distillate yield of hydrocracking product is $68.6 \%$. Meanwhile the selectivity to middle distillate can reach up to $81.5 \%$. Compared with CUSY-supported catalyst, the yield and selectivity of MNUSY-supported catalyst increased by 8.2 and $5.1 \%$, respectively. In addition, MNUSY-supported catalyst also presents higher yield and selectivity than CPUSY-supported catalyst, indicating a better hydrocracking performance of MNUSY than CPUSY. These results demonstrate that combined modification of USY zeolites using malic acid and nitric acid can meet the requirements of productive middle distillate in the industrial unit, which may have potential applications in the commercial methods of $\mathrm{Y}$ zeolites modification.

\section{Conclusion}

A combined modification of CUSY zeolite using malic acid and nitric acid was successfully developed. The optimum operation conditions were investigated via a single-factor experiment. The modified USY zeolite under 
Table 5 Hydrocracking performance of catalysts

\begin{tabular}{lccc}
\hline Products distribution $(\%)$ & CUSY & CPUSY & MNUSY \\
\hline HK- $140{ }^{\circ} \mathrm{C}$ & 18.68 & 16.08 & 15.54 \\
$140-370{ }^{\circ} \mathrm{C}$ & 60.42 & 66.09 & 68.59 \\
$>370{ }^{\circ} \mathrm{C}$ & 20.16 & 16.85 & 15.03 \\
Loss & 0.74 & 0.98 & 0.84 \\
Conversion of $>350{ }^{\circ} \mathrm{C}$ feedstock $(\%)$ & 75.0 & 75.9 & 77.1 \\
Selectivity to middle distillate $(\%)$ & 76.38 & 80.45 & 81.52 \\
\hline
\end{tabular}

Conversion $=\left(1->350{ }^{\circ} \mathrm{C}\right.$ fraction of production $/>350{ }^{\circ} \mathrm{C}$ fraction of feed oil $) \times 100 \%$. Yield $=\left(140-370{ }^{\circ} \mathrm{C}\right.$ middle distillates fraction of production $) \times 100 \%$. Middle distillates selectivity $=\left(140-370{ }^{\circ} \mathrm{C}\right.$ fraction of production $/<370{ }^{\circ} \mathrm{C}$ fraction of production $) \times 100 \%$

the optimum technological conditions presents an enhanced secondary pore volume and appropriate acid distribution as well as good crystallinity. In addition, the USY zeolite modified by malic acid and nitric acid possesses larger secondary pore volume and more appropriate acid properties than the USY modified with citric acid and phosphoric acid. Abundant mesoporous pore structure and appropriate acidic sites make MNUSY an excellent catalyst support in hydrocracking catalysts.

Acknowledgments This work was financially supported by PetroChina Refinery Catalyst Key Project (2010E-1903) and Key Program of NSFC (U1362202).

Open Access This article is distributed under the terms of the Creative Commons Attribution 4.0 International License (http:// creativecommons.org/licenses/by/4.0/), which permits unrestricted use, distribution, and reproduction in any medium, provided you give appropriate credit to the original author(s) and the source, provide a link to the Creative Commons license, and indicate if changes were made.

\section{References}

1. Chang J, Tsubaki N, Fujimoto K (2001) Elemental sulfur as an effective promoter for the catalytic hydrocracking of Arabian vacuum residue. Fuel 80:1639-1643

2. Yoshida R, Miyazawa M, Ishiguro H, Itoh S, Haraguchi K, Nagaishi H, Narita H, Yoshida T, Maekawa Y, Mitarai Y (1997) Chemical structure changes in Cold Lake oil-sand bitumen and catalytic activities during catalytic hydrotreatment. Fuel Process Technol 51:195-203

3. Yoshida R, Miyazawa M, Yoshida T, Narita H, Maekawa Y (1996) Chemical structure changes in Condor shale oil and catalytic activities during catalytic hydrotreatment. Fuel 75:99-102

4. Sahu R, Song BJ, Im JS, Jeon Y-P, Lee CW (2015) A review of recent advances in catalytic hydrocracking of heavy residues. J Ind Eng Chem 25:12-24

5. McGrath HG, Charles ME (1971) Origin and refining of petroleum. Am Chem Soc 3:67-80
6. Giannetto G, Montes A, Rodríguez G (1990) Zeolitas: características, propiedades y aplicaciones industriales EdiT-Ediciones Innovación Tecnológica, Caracas: Venezuela

7. McDaniel C, Maher P (1968) Molecular sieves. Society of Chemical Industry, London $\mathbf{1 8 6}$

8. Sasaki Y, Suzuki T, Takamura Y, Saji A, Saka H (1998) Structure analysis of the mesopore in dealuminated zeolite $\mathrm{Y}$ by high resolution TEM observation with slow scan CCD camera. J Catal 178:94-100

9. Stach H, Lohse U, Thamm H, Schirmer W (1986) Adsorption equilibria of hydrocarbons on highly dealuminated zeolites. Zeolites 6:74-90

10. Gola A, Rebours B, Milazzo E, Lynch J, Benazzi E, Lacombe S, Delevoye L, Fernandez C (2000) Effect of leaching agent in the dealumination of stabilized Y zeolites. Microporous Mesoporous Mater 40:73-83

11. Cruz J, Corma A (1989) Framework and extra-framework aluminium distribution in (NH4)2F6 Si-dealuminated Y zeolites: relevance to cracking catalysts. Appl Catal 50:287-293

12. Lónyi F, Lunsford JH (1992) The development of strong acidity in hexafluorosilicate-modified Y-type zeolites. J Catal 136:566-577

13. Kubelková L, Seidl V, Nováková J, Bednářová S, Jírů P (1984) Properties of Y-type zeolites with various silicon/aluminium ratios obtained by dealumination with silicon tetrachloride. Distribution of aluminium and hydroxyl groups and interaction with ethanol. J Chem Soc Faraday Trans 1 80:1367-1376

14. Anderson MW, Klinowski J (1986) Zeolites treated with silicon tetrachloride vapour: IV. Acidity. Zeolites 6:455-466

15. Engelhardt G, Lohse U (1984) A reexamination of the hypothesis of Breck and Skeels concerning the reinsertion of aluminum in the framework of dealuminated Y zeolites. J Catal 88:513-515

16. Yan Z, Ma D, Zhuang J, Liu X, Liu X, Han X, Bao X, Chang F, Xu L, Liu Z (2003) On the acid-dealumination of USY zeolite: a solid state NMR investigation. J Mol Catal A 194:153-167

17. Xin-Mei L, Zi-Feng Y (2001) Optimization of nanopores and acidity of USY zeolite by citric modification. Catal Today 68:145-154

18. Lercher J, Rumplmayr G (1986) Controlled decrease of acid strength by orthophosphoric acid on ZSM5. Appl Catal 25:215-222

19. Li X, Qiao K, He L, Liu X, Yan Z, Xing W, Qin L, Dai B, Zhang Z (2014) Combined modification of ultra-stable $Y$ zeolites via citric acid and phosphoric acid. Appl Petrochem Res 4:343-349 